\title{
МЕЖДУНАРОДНОЕ СОТРУДНИЧЕСТВО В СФЕРЕ ОХРАНЫ ЗДОРОВЬЯ НАСЕЛЕНИЯ И ВЗАИМООБУСЛОВЛЕННОСТЬ НАЦИОНАЛЬНЫХ СИСТЕМ ПРАВА СОЦИАЛЬНОГО ОБЕСПЕЧЕНИЯ
}

\begin{abstract}
Аннотация: В статье анализируются нормы международного права, посвященные вопросам здравоохранения. Предпринимается попытка их структурирования по различныл основаниям. Показывается связь международных норм и национальных правовых систем. Делается вывод о существовании нескольких уровней международных стандартов прав человека в сфере охраны здоровья и медищинской помощи, а именно минимальных стандартов (Конвенция МОТ № 102) и стандартов более высокого уровня (к примеру, Европейский кодекс соииального обеспечения 1968 г.). Приводятся примеры минимальных мероприятий оказываемых при предоставлении медицинской помощчи и расширенные перечни медицинских услуг, для государств, имеющих экономическую и организационную возможность их предоставить. В основу исследования положен системный метод, позволивиий проанализировать и выявить взаимосвязь норм международного права, регулирующих вопросы оказания медицинской и лекарственной помощи. В результате исследования международных норм различных видов (акты международных организаций, межгосударственных объединений и международные договоры) автором выявляется взаимосвязь медицинской и лекарственной помощи, где надлежащее обеспечение необходимыми медикаментами является неотъемлемым элементом медицинской помощи. Подчеркивается, что только тогда, когда такое предоставление осуществляется безвозмездно, можно говорить об оказании лекарственной помощчи на соичильно-обеспечительных началах. Автор приходит к выводу, что наиболее тесное международно-правовое сотрудничество в сфере регулирования вопросов здравоохранения развивается в рамках Союза Независимых Государств. Приводятся примеры международных актов ратифицированных Российской Федераџией и отражается их влияние на действуюшую национальную правовою систему. Проведенный анализ, позволяет автору сделать вывод о том, что Российская Федерация к настоящему времени ратифицировала небольшое количество международных актов, посвященных вопросам здравоохранения, что не способствует совершенствованию указанной системьл.
\end{abstract}

Ключевые слова: Медицинская помощь, лекарственное обеспечение, охрана здоровья граждан, международное сотрудничество, право сочиильного обеспечения, национальные системы, стандартыл, лекарство, орфанные заболевания, доступность лекарственных средств.

Abstract: In this article standards of international law on health issues are analyzed. The author presents the link between international standards and national legal systems. It is concluded that there are several levels of international human rights standards in the area of health and medical care, specifically the minimal standards (International Labor Organization Convention No. 102) and higher standards (for instance, the European Code of Social Security of 1968). Examples are given on the minimal measures undertaken in providing medical care, as well as expanded lists of medical services offered for the states that have the economic and organizational capabilities to provie them. The research is based on a systematic method, which allowed the author to analyze and identify the relations between the international laws governing the issues of medical and pharmaceutical assistance. As a result of the research on various types of international norms (e.g. acts of international organizations and intergovernmental organizations, and international agreements) the author reveals the correlation between medical and pharmaceutical assistance, whereas the appropriate supply of necessary medicines is an integral part of healthcare. It is emphasized that only if such provision is made on a free basis one can talk about the provision of pharmaceutical care on the social security basis.The author draws the conclusion that the closest international and legal cooperation in the sphere of healthcare regulation is developing within the Commonwealth of Independent States. The examples of international acts authorized by the Russian Federation are introduced, and its influence on the existing national and legal system is demonstrated. The analysis made allows the author to conclude that to date, the Russian Federation has authorized a rather small number of international acts on healthcare, and thus does not encourage the improvement of this system.

Keywords: Standards, national systems, social security law, International cooperation, public healthcare, medication supply, medical care, medications, rare diseases, medication accessibility. 


\section{Право и политика $3(183) \cdot 2015$}

$\Pi$ раво на охрану здоровья является одним из важнейших элементов правового статуса человека. В самом общем смысле оно может быть определено как комплекс правовых возможностей по получению мер медицинского и социального характера (медицинской помощи, санаторно-курортного лечения, пособий по болезни и т.д.), направленных на поддержание и укрепление здоровья человека. Прежде чем перейти к анализу международного сотрудничества в указанной сфере, необходимо определить, что собой представляет охрана здоровья населения. В Российской Федерации определение охраны здоровья закреплено в Федеральном законе от 21 ноября 2011 года № 323-Ф3 «Об основах охраны здоровья граждан в Российской Федерации». Согласно статье 2 охрана здоровья представляет собой систему мер политического, экономического, правового, социального, научного, медицинского, в том числе санитарно-противоэпидемического (профилактического), характера, осуществляемых органами государственной власти Российской Федерации, органами государственной власти субъектов Российской Федерации, органами местного самоуправления, организациями, их должностными лицами и иными лицами, гражданами в целях профилактики заболеваний, сохранения и укрепления физического и психического здоровья каждого человека, поддержания его долголетней активной жизни, предоставления ему медицинской помощи [1]. Таким образом, охрана здоровья населения обеспечивается осуществлением различных мер, в том числе социального и медицинского характера. Среди факторов, обуславливающих состояние здоровья населения, (40-50\%) составляют факторы образа жизни, а именно условий труда и быта, включая антропогенное воздействие [2, с. 11]. Примерно по $20 \%$ приходится на особенности места проживания и наследственные факторы и около 7 - 15 \% - качество медицинской деятельности, работу учреждений здравоохранения [3, с. 7]. Таким образом, социальные факторы и медицинская помощь оказывают существенное влияние на обеспечение здоровья граждан.

В настоящее время вопросы охраны здоровья населения и оказания медицинской помощи нашли свое отражение не только во внутренних правовых системах государств, но и в международных актах. В Российской Федерации вопросам охраны здоровья и медицинской помощи посвящено большое количество нормативных правовых актов, базовые положения которых сформировались во многом под влиянием норм международного права. Так, в Законе об основах охраны здоровья граждан предусмотрено осуществление международ- ного сотрудничества Российской Федерации в сфере охраны здоровья, включая заключение международных договоров Российской Федерации. Существуют несколько вариантов осуществления международного сотрудничества: 1) в рамках межгосударственных объединений (Содружество Независимых Государств; Европейский Союз); 2) в рамках международных организаций (Международная организация труда, Всемирная организация здравоохранения); 3) путем заключения международных договоров и соглашений.

Однако степень воздействия международных норм на национальную правовую систему неодинакова. Так, согласно статье 15 Конституции Российской Федерации общепризнанные принципы и нормы международного прав и международные договоры Российской Федерации являются составной частью ее правовой системы.

Наиболее сильное влияние на развитие внутригосударственного законодательства оказывают международные договоры, в отношении которых Российская Федерация в лице компетентных органов власти выразила согласие на обязательность для нее международного договора посредством одного из действий (подписание договора; обмен документами, его образующими; ратификация договора, утверждение договора; принятие договора; присоединение к договору) при условии, что указанный договор вступил в силу для Российской Федерации, иные правовые положения, могут рассматриваться в качестве ориентиров в совершенствовании национальной правовой системы [4].

В результате анализа международных актов, приходим к выводу, что нормы, прямо или косвенно касающиеся охраны здоровья, содержатся во многих международно-правовых актах. Это и акты общего характера, устанавливающие как универсальный каталог прав человека, так и права отдельных социально-демографических групп населения. Международные акты общего характера (Всеобщая декларация прав человека 1948 г.; Международный пакт о гражданских и политических правах 1966 г;; Международный пакт об экономических, социальных и культурных правах 1966 г.; Хартия о социальных правах граждан независимых государств 1994 г.; Европейская конвенция о защите прав и основных свобод), предоставляют индивиду определенные права, включая право на социальное обеспечение, медицинскую помощь и т.д.

Помимо актов общего характера можно выделить те, которые регулируют права индивидов, обладающих определенными особенностями, в том числе право на охрану здоровья и медицинскую помощь. К примеру: 
А) Акты, регламентирующие правовой статус определенных категорий граждан в зависимости от того, к какой социально-демографической группе они относятся (Конвенция о правах ребенка 1989 г;; Резолюция Генеральной Ассамблеи ООН от 20 декабря 1993 г. N 48/96 «Стандартные правила обеспечения равных возможностей для инвалидов»);

Б ) Акты, закрепляющие правовой статус индивидов в зависимости от особенностей осуществляемой ими трудовой деятельности и условий ее осуществления, места нахождения лица (Конвенция о правовом статусе трудящихся-мигрантов и членов их семей государствучастников СНГ 2008 г.; Конвенция МОТ о труде в морском судоходстве 2006 г;; Минимальные стандартные правила обращения с заключенными 1955 г.).

Существуют международно-правовые акты, которые непосредственно направлены на регулирование отношений в сфере охраны здоровья населения и организации медицинской помощи. Предлагаем именовать данные акты специализированными (Конвенция МОТ № 130 о медицинской помощи и пособиях по болезни 1969 г.; Конвенция о защите прав человека и человеческого достоинства в связи с применением биологии и медицины; Конвенция о правах человека и биомедицине 1996 г.; Соглашение государств - участников СНГ о сотрудничестве в области охраны здоровья 1992 г;; Соглашение о сотрудничестве в области оказания высокотехнологичной медицинской помощи гражданам государств - членов Евразийского экономического сообщества 2012 г.).

К международно-правовым актам этой группы можно отнести акты, регулирующие правовой статус лиц, страдающих отдельными видами заболеваний (Соглашение государств-участников СНГ о сотрудничестве в решении проблем ВИЧ-инфекции 1998 г.; Резолюция Генеральной Ассамблеи ООН «Политическая декларация по ВИЧ/СПИДу» 2006 г.; Рекомендация Совета Европейского союза о деятельности в области редких болезней 2009 г.; Модельный закон об основах медико-социальной защиты граждан, больных сахарным диабетом 2004 г.); акты, предусматривающие гарантии в области оказания медицинской помощи лицам, занимающимся определенными видами трудовой деятельности или проживающим на отдельных территориях (Соглашение между Министерством здравоохранения и медицинской промышленности Российской Федерации, Министерством обороны Российской Федерации (Военно-Космические Силы), Российским космическим агентством и Министерством здравоохранения Республики
Казахстан, администрацией города Ленинска о порядке медицинского обслуживания персонала комплекса «Байконур» и других жителей г. Ленинска в условиях аренды Российской Федерацией комплекса «Байконур» 1995 г.; Конвенция МОТ № 164 О здравоохранении и медицинском обслуживании моряков 1987 г.); акты, устанавливающие гарантии в области оказания медицинской помощи для лиц, имеющих особые заслуги (Решение об Основных направлениях дальнейшего развития медико-социальной помощи и повышения качества жизни ветеранов войн - участников локальных конфликтов и членов их семей в государствах - участниках СНГ на период до 2015 года).

Также необходимо отметить, что существуют несколько уровней международных стандартов прав человека в сфере охраны здоровья и медицинской помощи. Минимальные стандарты, зафиксированные, в частности, в Конвенции МОТ № 102 оптимальны по содержанию и представляют собой рамки, в которых государства оказались способными достичь компромисса, они позволяют гарантировать хотя бы минимальный уровень реализации прав [5]. Их существование не ограничивает государство в создании стандартов, которые бы гарантировали более высокий уровень защиты прав своих граждан (Европейский кодекс социального обеспечения 1968 г.). Таким образом, государство само решает, обязательства по выполнению какого международного акта принять на себя, в зависимости от экономических и организационных особенностей. По мнению Е.Е. Мачульской, задачами международно-правового регулирования помимо разработки международных стандартов, являются гармонизация и координация законодательства различных стран [6, с. 479]. Гармонизация заключается в формировании общих принципов, а также минимальных стандартов, которые могут быть восприняты и реализованы в национальном законодательстве разных стран. Основной целью координации национальных систем социального обеспечения является их приспособление друг к другу [6, с. 481].

Рассмотрим основные нормы международного права, посвященные вопросам здравоохранения, которые направлены на гармонизацию и координацию современных национальных правовых систем.

Достаточно большое количество актов Международной организации труда (далее также MOT) посвящено вопросам оказания медицинской помощи как всем гражданам, так и определенным категориям лиц (к примеру, морякам). По мнению 


\section{Право и политика $3(183) \cdot 2015$}

Е.Е. Мачульской, самым ярким примером установления стандартов, на которые должны ориентироваться страны, является Конвенции МОТ № 102 о минимальных нормах социального обеспечения от 28 июня 1952 года [7]. Она определяет примерный круг лиц, которым оказывается бесплатная медицинская помощь [6, с. 480]: 1) установленные категории работающих по найму, составляющие не менее 50 процентов от общего числа работающих по найму, а также их жены и дети; 32) установленные категории самодеятельного населения, составляющие не менее 20 процентов от общего числа жителей, а также их жены и дети; 3) установленные категории жителей, составляющие не менее 50 процентов от общего числа жителей.

Если экономика и медицинское обслуживание государства еще не достигли достаточной степени развития то обеспечиваться медицинской помощью должны не менее 50 процентов от общего числа работающих по найму на промышленных предприятиях, на которых занято не менее 20 человек, а также их жены и дети.

Также в Конвенции МОТ № 102 регламентирован минимальный перечень мероприятий, которые должны производиться в случае возникновения у лица болезненного состояния, в который входят: 1) общая врачебная помощь, включая визиты на дому; 2) помощь, оказываемая специалистами стационарным или амбулаторным больным в больницах, и помощь, которая может оказываться специалистами вне больниц; 3) обеспечение наиболее необходимыми медикаментами, предписанными врачом или другим дипломированным специалистом; 4) госпитализация в случае необходимости.

Отметим, что, помимо помощи, оказываемой врачом-специалистом в различных условиях, минимальные нормы медицинского обслуживания охватывают обеспечение необходимыми лекарственными средствами. Представляется, что речь идет о бесплатном предоставлении медикаментов лицам, имеющим право на получение медицинской помощи. При этом, если лекарственный препарат предоставляется на безвозмездных началах, то можно говорить, что эта гарантия является составным элементом системы социального обеспечения государства.

Аналогичные положения содержатся в Конвенции МОТ № 130 о медицинской помощи и пособиях по болезни от 25 июля 1969 года (далее - Конвенция МОТ № 130) [7]. Однако она устанавливает иной круг лиц, которые обеспечиваются медицинской помощью, и относит к их числу: 1) всех работающих по найму, включая учеников, а также их жен и детей; 2) установленные категории экономически активного населения, составляющие в общей сложности не менее 75 процентов всего экономически активного населения, а также жены и дети лиц вышеуказанных категорий; 3) установленные категории жителей, составляющие в общей сложности не менее 75 процентов всех жителей.

Следует сказать, что Конвенция МОТ № 130 предусматривает общий перечень мер, предоставляемых при оказании медицинской помощи, куда помимо мер, указанных в Конвенции МОТ № 102, входит еще и зубоврачебная помощь, а также медицинское восстановление, в том числе предоставление, ремонт и замена протезов или ортопедических приспособлений, как это установлено национальным законодательством. Государства, экономика и система медицинского обслуживания которых не достигли достаточного развития могут установить временные изъятия применительно к отдельным видам медицинской помощи, а именно зубоврачебной помощи и медицинскому восстановлению. Таким образом, можно утверждать, что неотъемлемыми элементами медицинской помощи являются непосредственно помощь, оказываемая специалистом в различных условиях (амбулаторно, стационарно и т.д.), а также лекарственное обеспечение.

Анализ международных стандартов позволяет сделать вывод, что медицинская помощь, включая предоставление лекарств, является частью системы социального обеспечения, следовательно, на нее также распространяются указанные стандарты, которые служат основой для формирования национальных правовых систем. Посредством применения международных стандартов достигается закрепление в национальных правовых системах государств с различным уровнем экономического развития единого набора прав и их минимально допустимого объема и содержания. Реализация этого правила наиболее важна в отношении правовой регламентации медицинской и лекарственной помощи, как призванных сохранить и восстановить здоровье человека.

Кроме того, международное сотрудничество осуществляется в борьбе с эпидемиями, в поиске новых лекарств и методов лечения некоторых болезней (ВИЧ/ СПИД, орфанные заболевания и т.д.). Оно направлено на обеспечение доступности для всех лиц, страдающих теми или иными заболеваниями, к новым методам лечения, лекарственным препаратам, вакцинам и т.д.

В Резолюции Генеральной Ассамблеи ООН от 2 июня 2006 года №60/262 «Политическая декларация по ВИЧ/СПИДу» устанавливается, что национальные и международные усилия в период с 2001 года привели 
к значительному прогрессу в областях финансирования, расширения доступа к профилактике ВИЧ, лечению, уходу и поддержке, а также в смягчении последствий СПИДа и в сокращении показателей инфицирования ВИЧ в небольшом, но возрастающем числе стран. Резолюцией провозглашается доступ к лекарственным препаратам для лечения ВИЧ/СПИД, который является одним из основополагающих элементов постепенного обеспечения полного осуществления права каждого человека на наивысший достижимый уровень физического и психического здоровья [7]. В качестве направления деятельности определено создание более совершенных средств на будущее - лекарств, технологий в области диагностики и профилактики, включая вакцины и бактерициды.

Подобные положения содержатся и в Решении о Программе совместных действий государств - участников Содружества Независимых Государств по борьбе с ВИЧ/СПИД от 20 ноября 2009 года, где сказано о необходимости обеспечить доступ всех нуждающихся к надлежащему лечению.

Говоря о международном сотрудничестве в области борьбы с некоторыми болезнями, необходимо отметить международные акты, касающиеся регламентации правового статуса лиц, страдающих редкими (орфанными) заболеваниями. Так, в Рекомендациях Совета Европейского союза о деятельности в области редких болезней от 8 июня 2009 года говорится о создании доступа к орфанной медицинской продукции [7]. Для орфанных больных медикаментозное лечение зачастую является единственным вариантом получения медицинской помощи. Однако лекарственные средства для такие лиц могут оставаться недоступными в силу нескольких причин: 1) лекарственное средство для лечения заболевания еще не разработано; 2) конкретный медикамент не зарегистрирован на территории государства и приобрести его невозможно; 3) стоимость препаратов для лечения редких заболеваний является очень высокой, а социальные программы государства не предусматривают его бесплатного предоставления. Для решения этих проблем в Европейском союзе был принят Регламент об орфанных лекарственных средствах от 16 декабря 1999 года, который устанавливает, что пациенты, страдающие редкими заболеваниями, должны иметь право на такое же качество лечения, как другие больные, поэтому необходимо стимулировать исследования, разработку и размещение на рынке соответствующих препаратов фармацевтической промышленности [7]. Также данным актом вводится правило о взаимо- действии национальных систем здравоохранения в решении проблем орфанных больных. Российское законодательство долгое время не знало термина «орфанное» заболевание и, соответственно, не регламентировало правовой статус таких больных. Только в 2011 году Закон об основах охраны здоровья граждан ввел термин «редкие (орфанные) болезни». 22 декабря 2014 в Федеральный закон от 12 апреля 2010 № 61-Ф3 «Об обращении лекарственных средств» [8] внесены изменения он дополнен термином «орфанный лекарственный препарат», также предусмотрен механизм упрощенной регистрации таких медикаментов.

Как уже было сказано, координационные международные нормы направлены на сближение национальных правовых систем и «смягчение» принципа территориальности, так как он служит препятствием для реализации права на свободу передвижения [6, c. 481]. Безусловно, важное значения играют международные координационные нормы, устанавливающие порядок оказания медицинской помощи иностранным гражданам, лицам без гражданства, мигрантам и т.д.

Наиболее тесное международно-правовое сотрудничество в сфере регулирования вопросов здравоохранения развивается в рамках Содружества Независимых Государств (далее - СНГ). Это объясняется общностью исторических, культурных, научных, экономических и транспортных связей.

В Соглашении о сотрудничестве в области здравоохранения от 26 июня 1992 года [7] устанавливается приоритет охраны здоровья населения, механизм взаимодействия национальных систем здравоохранения в оказании медицинской помощи.

Преамбула Соглашения об оказании медицинской помощи гражданам государств-участников Содружества независимых государств от 27 марта 1993 года в качестве цели заключения Соглашения признает содействие дальнейшему развитию и углублению взаимодействия в области оказания медицинской помощи населения [7]. В свою очередь в качестве лиц-получателей особо выделены беженцы, лица, временно пребывающих на территории государства, лица, имеющие вид на жительство. Указанный статус определяет объем медицинской помощи, которую пациент может получить на безвозмездных началах.

Придавая особое значение вопросу обеспечения населения лекарственными средствами, страны СНГ заключили Соглашение об обеспечении населения лекарственными средствами, вакцинами и другими иммунобиологическими препаратами, изделиями медицинского назначения и медицинской техники, 


\section{Право и политика 3 (183) 2015}

производимыми на территории государств - участников Содружества Независимых Государств 1993 г [7]. Указанное Соглашение предусматривает создание различных стимулирующих мер для развития медицинской промышленности, введение таможенных льгот на ввозимую продукцию и т.д.

Российская Федерация осуществляет международное сотрудничество в области охраны здоровья населения посредством заключения международных договоров. Так, в целях содействия развитию и расширению сотрудничества между государствами в области здравоохранения и социального обеспечения и, сознавая целесообразность объединения усилий государств в решении проблем указанной сферы, было заключено Соглашение между Правительством Российской Федерации и Правительством Королевства Швеция о сотрудничестве в области здравоохранения и социального обеспечения 2010 г [7]. Соглашение предусматривает различные виды взаимодействия, к примеру: обмен специалистами и делегациями; обмен информацией; установления прямых связей между производителями медицинской техники, оборудования и предметов медицинского назначения, в особенности для инвалидов; участия специалистов в конгрессах и научных конференциях и т.д. Аналогичные нормы содержатся в Соглашении между Правительством Российской Федерации и Правительством ЮжноАфриканской Республики о сотрудничестве в области здравоохранения и медицинской науки 2006 г [7].
Подводя итог, констатируем, что фундаментальные международные акты признают приоритет права на охрану здоровья граждан и на доступность медицинской помощи. В результате анализа международных норм различных видов (акты международных организаций и межгосударственных объединений) была выявлена взаимосвязь медицинской и лекарственной помощи, в рамках которой надлежащее обеспечение необходимыми медикаментами является неотъемлемым элементом медицинской помощи.

Минимальные стандарты в области социального обеспечения регламентируют право граждан на медицинскую и лекарственную помощь, тем самым гарантируя их предоставление в рамках национальных правовых систем государств с различным уровнем экономического развития. Таким образом, осуществляется гармонизация внутригосударственных законодательств и национальных систем охраны здоровья на основе международно-правовых стандартов.

Посредством осуществления международного сотрудничества в области охраны здоровья населения происходит сближение национальных правовых систем, их взаимообусловленность. Принятие государством обязательств по международному соглашению порождает изменение внутреннего законодательства. Таким образом, чем активней становится международное сотрудничество, тем сильнее сближаются и взаимопроникают национальные правовые системы, в том числе в таких сферах как охрана здоровья и социальное обеспечение.

\section{Библиография:}

1. Федеральный закон от 21 ноября 2011 г. № 323-Ф3 «Об основах охраны здоровья граждан в Российской Федерации» // СЗ РФ. 2011. № 48. Ст. 6724. (Далее - Закон об основах охраны здоровья граждан).

2. Мохов А.А. Основы медицинского права в Российской Федерации : учебное пособие для магистров. М.: ПРОСПЕКТ, 2013.

3. Федорова М.Ю. Медицинское право: учебное пособие для вузов. М.: Гуманит. изд. Центр ВЛАДОС, 2003.

4. Постановление Пленума Верховного Суда РФ от 10 октября 2003 года № 5 «О применении судами общей юрисдикции общепризнанных принципов и норм международного права и международных договоров Российской Федерации» // Бюллетень Верховного Суда РФ. 2003. № 12.

5. Тиунов О.И. Роль международно-правовых стандартов в регулировании взаимодействия международного и национального права // Журнал российского права. 2012. N 12. С. 69 - 83 / Доступ из СПС «КонсультантПлюс».

6. Мачульская Е.Е. Право социального обеспечения: учебник. М.: ЮРАЙТ, 2011.

7. Доступ из СПС «КонсультантПлюс».

8. Собрание законодательства РФ. 2010. № 16. Ст. 1815.

\section{References (transliterated):}

1. Mokhov A.A. Osnovy meditsinskogo prava v Rossiiskoi Federatsii : uchebnoe posobie dlya magistrov. M.: PROSPEKT, 2013.

2. Fedorova M.Yu. Meditsinskoe pravo: uchebnoe posobie dlya vuzov. M.: Gumanit. izd. Tsentr VLADOS, 2003.

3. Tiunov O.I. Rol' mezhdunarodno-pravovykh standartov v regulirovanii vzaimodeistviya mezhdunarodnogo i natsional'nogo prava // Zhurnal rossiiskogo prava. 2012. N 12. S. 69 - 83 / Dostup iz SPS «Konsul'tantPlyus».

4. Machul'skaya E.E. Pravo sotsial'nogo obespecheniya: uchebnik. M.: YuRAIT, 2011. 